\title{
Otomasi Manajemen dan Pengawasan Linux Container (LCX) Pada Proxmox VE Menggunakan Ansible
}

\section{Linux Container Management and Monitoring Automation (LCX) on Proxmox VE Using Ansible}

\author{
Muh. Akromi Arya Pratama ${ }^{1 *}$, Putu Hariyadi ${ }^{2}$ \\ 1,2 Jurusan Ilmu Komputer, Universitas Bumigora \\ akromiaryapratama8@gmail.com ${ }^{1 *}$, putu.hariyadi@stmikbumigora.ac.id ${ }^{2}$
}

\begin{abstract}
Abstrak - Penerapan sistem otomasi menggunakan ansible dapat mengefisienkan proses tersebut yang dilakukan secara manual. Ansible merupakan mesin otomatisasi Teknologi Informasi (TI) sederhana yang dapat mengotomatisasi cloud provisioning, manajemen konfigurasi, penerapan aplikasi, intraservice orchestration dan kebutuhan TI lainnya. Fitur yang diotomasi adalah pembuatan, menjalankan, menghentikan dan menghapus CT. dan juga pembuatan, mereset dan menghapus user dan permission akun dengan skenario ujicoba pada setiap perangkat yang terlibat berdasarkan rancangan ujicoba dan analisa terhadap hasil ujicoba yang telah dilakukan. Metode penelitian yang digunakan adalah prototype. Tahapan-tahapan pada metode prototype yaitu pengumpulan kebutuhan, membuat prototype, evaluasi prototype, pengkodean dan uji coba sistem. Hasil dari penelitian ini berupa sistem yang dapat mengotomasi pembuatan, menjalankan, menghentikan dan menghapus CT. dan juga mengotomasi pembuatan, mereset dan menghapus user dan permission. Manajemen CT, user dan permission dengan otomasi menggunakan tool ansible juga membuat proses manajemen $C T$, user dan permission menjadi lebih efisien dibandingkan dilakukan secara manual. Ansible dapat digunakan untuk mengotomasi manajemen CT baik dalam pembuatan, menjalankan, menghentikan dan menghapus CT pada PVE dan juga Ansible dapat digunakan untuk mengotomasi manajemen user \& permission baik dalam pembuatan, mereset dan menghapus user \& permission pada PVE. dalam mata pelajaran administrasi system jaringan di SMKN 6 Mataram.
\end{abstract}

Kata Kunci: Otomasi, CT, Ansible, Proxmox Virtual Environtment.

\begin{abstract}
The implementation of the automation system uses processes that can be carried out efficiently which are carried out manually. Enabling is a simple Information Technology (IT) automation engine that can automate cloud provisioning, configuration management, application implementation, intra-service orchestration and other IT needs. The automated features are creating, running, stopping and installing CT. and also creates, resets and installs user and account permissions with a trial scenario on each device involved based on the trial design and analyzes the results of the trials that have been carried out. The research method used was a prototype. The stages in the prototype method are planning requirements, making prototypes, evaluating prototypes, coding and testing systems. The results of this study consist of a system that can automate the manufacturing, running, stopping and installing CT. and also automates creation, resetting and installing user permissions and. CT management, users and permits with automation using tools might also make the CT, user and permission management process more efficient than done manually. Can be used to automate CT management both in manufacturing, running, stopping and installing CT in PVE and also in the network administration system subjects at SMK 6 Mataram.
\end{abstract}

Keywords: Automation, CT, Ansible, Proxmox Virtual Environtment.

Jurnal Bumigora Information Technology (BITe)

Vol.3, No.1, Juni 2021, pp. 82-95

ISSN: $2685-4066$

DOI: 10.30812/bite.v3i1.807 


\section{Pendahuluan}

Sekolah Menengah Kejuruan Negeri (SMKN) 6 Mataram merupakan salah satu sekolah yang beralamat di Jl. Lalu Mesir, Babakan, Kota Mataram. SMKN 6 Mataram memiliki 7 (tujuh) jurusan yaitu Teknik Jaringan dan Komputer (TKJ), Teknik Perbaikan Bodi Otomotif, Teknik Pengelasan, Teknik kendaraan Ringan, Teknik pendingin dan tata udara, Bisnis kontruksi dan property, dan Desain grafis. Pihak sekolah menyediakan laboratorium komputer dan perangkat jaringan untuk menunjang kegiatan praktikum pada program studi TKJ. Selain itu untuk mendukung praktikum dari salah satu mata pelajaran yaitu administrasi system jaringan, guru dari program studi TKJ juga telah memanfaatkan media virtualisasi berbasis Proxmox Virtual Environtment[1][2].

Secara umum, sebelum dapat memanfaatkan media pembelajaran virtualisasi berbasis $P V E$ tersebut maka diperlukan pengaturan yang harus di persiapkan oleh pihak guru agar siswa dapat menggunakkan PVE sebagai media pembelajaran[3]-[5]. Untuk guru terdapat beberapa hal yang perlu dipersiapkan terlebih dahulu, seperti pembuatan container $(C T)[6]$, [7], user, dan pengaturan permission yang di lakukan di setiap awal semester, dibutuhkan monitoring $C T$ yang sedang aktif dan tidak aktif saat pertemuan setiap minggunya, dan penghapusan $C T$, user dan permission yang dilakuakan di setiap akhir semester. Untuk saat ini Teknik yang digunakan untuk menyiapkan media pembelajaran berbasis Proxmox VE masih dilakukan secara manual melalui Graphical User Interface (GUI) dari Proxmox VE.

Dari permasalahan yang ada dikarenakan masih dilakukan secara manual dan membutuhkan waktu yang cukup lama sehingga untuk proses pembelajaran dirasa kurang efisisen, dari pihak sekolah khususnya guru yang mengampu mata pelajaran tersebut memiliki harapan adanya sistem yang dapat mengotomasi pembuatan $C T$, user dan pengaturan permission sehingga setiap memasuki tahun ajaran baru di awal semester guru dapat membuat $C T$, user dan pengaturan permission sejumlah siswa yang mengampu mata pelajaran tersebut, selama satu semester di pertemuan setiap minggunya mata pelajaran berlangsung saat proses praktikum dapat dimonitoring $C T$ yang aktif, dan di akhir semester dapat menghapus $C T$, user dan permission saat siswa yang mengampu mata pelajaran tersebut lulus dari mata pelajaran tersebut. Sehingga semuanya dapat diakomodir oleh guru yang mengampu mata pelajaran tersebut baik pembuatan $C T$, User dan pengaturan permission, monitoring $C T$ dan menghapus $C T$, user dan permission tanpa dilakukan dengan cara manual lagi.

Otomasi manajemen dan pengawasan $C T$ pada PVE menggunakan Ansible dapat membantu mengatasi permasalahan yang dihadapi oleh guru terkait manajemen dan pengawasan $C T$ pada PVE tersebut. Menurut Kamus Besar Bahasa Indonesia (2019), otomatisasi adalah penggantian tenaga manusia dengan tenaga mesin yang secara otomatis melakukan dan mengatur pekerjaan sehingga tidak memerlukan lagi pengawasan manusia (dalam industri dan sebagainya). Ansible merupakan mesin otomatisasi Teknologi Informasi (TI) sederhana yang dapat mengotomatisasi cloud provisioning, manajemen konfigurasi, penerapan aplikasi, intra-service orchestration dan kebutuhan TI lainnya.

Dengan adanya penelitian ini diharapkan dapat memberikan manfaat berupa pengetahuan dan wawasan dalam memanajemen dan pengawasan sistem virtualisasi otomasi pada $P V E$ sehingga proses pembelajaran lebih efektif dan efisien. 


\section{Metode Penelitian}

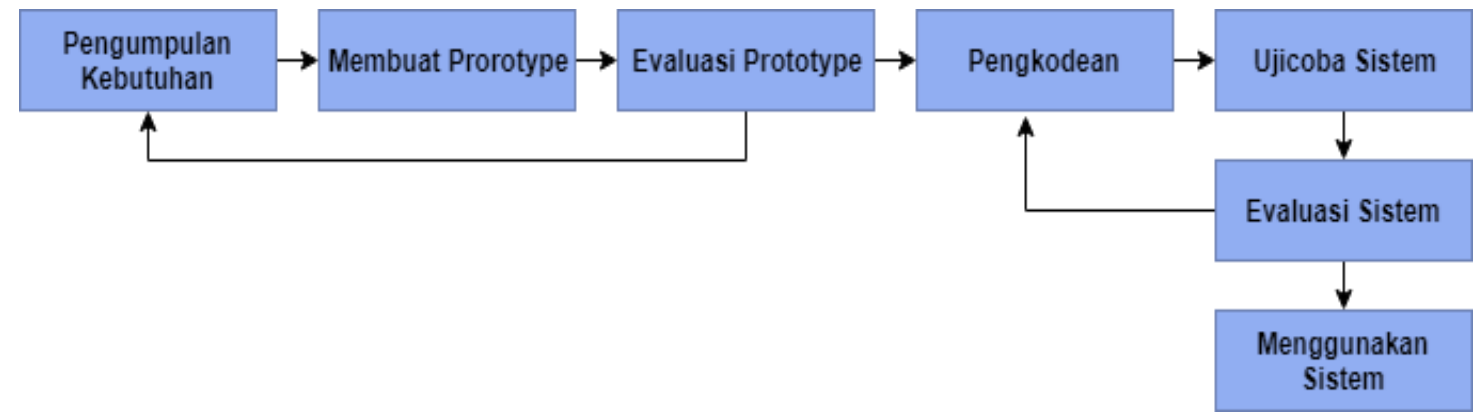

Gambar 1 Metodologi Prototype

Metodologi penelitian yang digunakan pada penelitian ini yaitu prototype. Dari tujuh tahapan yang ada, Terdapat lima dari tujuh tahapan yang digunakan yaitu Tahap Pengumpulan Kebutuhan, Membuat Prototype, Evaluasi Prototype, Pengkodean, Ujicoba Sistem.

\subsection{Pengumpulan Kebutuhan}

\subsubsection{Pengumpulan Data}

Terdapat 3 metode pengumpulan data yang digunakan yaitu observasi, wawancara dan dokumentasi. Adapun penjelasan dari masing-masing metode pengumpulan data yang digunakan adalah sebagai berikut:

\section{A. Observasi}

Metode observasi digunakan untuk mengumpulkan data dengan cara melakukan pengamatan secara langsung pada SMKN 6 Mataram sehingga dapat diperoleh informasi terkait sistem yang telah berjalan seperti perangkat jaringan, infrastruktur jaringan dan sistem yang digunakan. Dari hasil observasi yang telah dilakukan pada SMKN 6 Mataram maka diperoleh informasi sebagai berikut:

a) SMKN 6 Mataram memiliki ruang laboratorium komputer yang di peruntukan untuk mata pelajaran administrasi system jaringan yang didalamnya memuat perangkat infrastruktur jaringan, server dan komputer client.

b) Server telah menerapkan virtualisasi menggunakan PVE untuk mendukung proses pembelajaran administrasi system jaringan.

c) Terdapat server 24 komputer client pada laboratorium TKJ SMKN 6 Mataram yang terhubung ke server.

\section{B. Wawancara}

Metode pengumpulan data menggunakan wawancara dilakukan untuk memperoleh informasi lebih detail terkait sistem yang telah berjalan, kendala-kendala yang dihadapi, harapan dari SMKN 6 Mataram sehingga dapat ditentukan solusi penyelesaiannya. Wawancara dilakukan dengan Guru pengampu mata pelajaran administrasi system jaringan yaitu dengan Bapak I Gusti Bagus Wirayuda, A.Md. Daftar pertanyaan dan jawaban dari wawancara, seperti terlihat pada tabel 1 . 
Tabel 1 Wawancara Dengan Guru Pengampu Mata Pelajaran Administrasi System Jaringan

\section{Pertanyaan}

1 Berapa jurusan yang ada di SMKN 6 Mataram saat ini?

$2 \quad$ Terkait dengan prodi TKJ kendala-kendala apa saja yang dihadapi saat proses belajar mengajar?

3 Berdasarkan kurikulum yang digunakan mata pelajaran apa yang membutuhkan praktikum?

4 Apakah ada RPP dan modul untuk mendukung proses pembelajaran praktikum administrasi jaringan?

5 Berapa laboratorium dan berapa computer yang diperuntukan untuk mata pelajaran praktikum admistrasi system jaringan?

6 Ada berapa jumlah siswa yang mengikuti praktikum administrasi system jaringan?

$7 \quad$ Apakah proses belajar mengajar praktikum administrasi system jaringan telah menggunakan virtualisasi seperti VMware, Virtualbox atau yang lain?

\section{Jawaban}

Di SMKN 6 Mataram ada 7 jurusan yaitu Teknik Jaringan dan Komputer, Teknik Perbaikan Bodi Otomotif, Teknik Pengelasan, Teknik kendaraan Ringan, Teknik Pendingin dan Tata Udara, Bisnis Konstruksi dan Properti, dan Desain Grafis.

Dalam proses praktikum belum ada manajemen terpusat dalam virtualisasi dan kekurangan perangkat pembelajaran dalam lab.

Salah satu mata pelajaran yang sangat membutuhkan praktikum adalah mata pelajaran administrasi sistem jaringan.

Ada, RPP yang terselenggara pada semester ganjil dan genap.

Ada 1 LAB yang diperuntukan untuk mata pelajaran administrasi system jaringan dengan 1 komputer sebagai server dan 24 komputer sebagai client.

Ada 24 siswa yang mengikuti mata pelajaran administrasi system jaringan.

Iya, selama ini proses belajar mengajar praktikum administrasi system jaringan menggunakan virtualisasi seperti VMware Workstation dan Proxmox $V E$. 


\begin{tabular}{|l|l|l|}
\hline $\mathbf{8}$ & $\begin{array}{l}\text { Pada proses belajar } \\
\text { mengajar praktikum } \\
\text { administrasi sistem } \\
\text { jaringan menggunakan } \\
\text { virtualisasi Proxmox, } \\
\text { apakah ada kendala atau } \\
\text { permasalahan yang } \\
\text { dialami? }\end{array}$ & $\begin{array}{l}\text { Kendala pada pembuatan CT, user, pengaturan } \\
\text { permission dan monitoring user yang masih dilakukan } \\
\text { secara manual di setiap semesternya. }\end{array}$ \\
\hline $\mathbf{9}$ & $\begin{array}{l}\text { Apakah ada kendala } \\
\text { terkait sistem yang tepat } \\
\text { untuk mempercepat } \\
\text { pembuatan CT, User dan } \\
\text { pengaturan permission } \\
\text { pada server Proxmox? }\end{array}$ & $\begin{array}{l}\text { Iya masih terkendala menemukan system yang tepat } \\
\text { untuk mengatasi kendala tersebut. }\end{array}$ \\
\hline $\mathbf{1 0}$ & $\begin{array}{l}\text { Harapan apa untuk } \\
\text { kedepan terkait } \\
\text { permasalahan ini? }\end{array}$ & $\begin{array}{l}\text { Diharapkan adanya system yang tepat yang dapat } \\
\text { mengotomasi pembuatan CT, user, pengaturan } \\
\text { permission dan adanya system monitoring di setiap } \\
\text { semesternya. }\end{array}$ \\
\hline
\end{tabular}

\section{Dokumentasi}

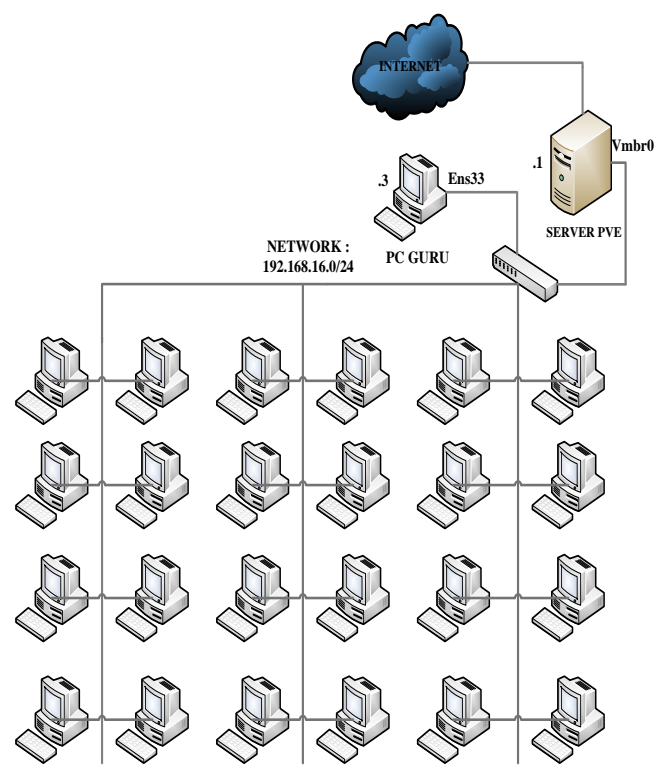

Gambar 2 Topologi LAB TKJ Pada SMKN 6 Mataram

Metode Metode pengumpulan data melalui dokumentasi dilakukan untuk memperoleh dokumen terkait rancangan topologi jaringan yang telah diterapkan pada SMKN 6 Mataram. Topologi jaringan yang digunakan oleh SMKN 6 Mataram seperti terlihat pada gambar 2.

Pada laboratorium komputer TKJ, terdapat 1 buah server PVE, dengan 24 client untuk siswa dan $1 P C$ untuk guru, yang terhubung langsung pada switch.

\subsection{Membangun Prototype}

Tahap ini memuat tentang rancangan jaringan lama, rancangan jaringan alternatif, rancangan uji coba, rancangan sistem otomasi, rancangan pengelamatan IP, serta kebutuhan perangkat keras dan perangkat lunak berdasarkan dari hasil analisa data pada tahap sebelumnya. 


\subsubsection{Rancangan Jaringan Lama}

Rancangan jaringan lama berisikan, topology jaringan yang digunakan saat ini di SMKN 6 Mataram, rancangan jaringan tersebut merupakan gambaran sebelum diterapkannya system otomasi. Berikut ini merupakan rancangan jaringan lama yang digunakan.

Rancangan jaringan lama berisikan server PVE yang terhubung langsung ke internet, dengan 1 komputer guru sebagai administrator dan terdapat 24 client yang terhubung melalui switch.

\subsubsection{Rancangan Sistem Manual PVE}

Rancangan sistem manual PVE berisikan rancangan yang akan digunakan dalam pembuatan $C T$ pada server PVE. Seperti terlihat pada gambar 6.

Dalam pembuatan akun pada $C T$, digunakan data siswa berupa NIS (Nomor Induk Siswa) sebagai pengenal akun pada $C T$ untuk masing-masing siswa. Data tersebut dapat dilihat seperti pada tabel berikut.

Tabel 2 Data Pembuatan Akun Otentikasi

\begin{tabular}{|c|c|c|}
\hline $\begin{array}{c}\text { User Menggunakan NIS (Nomor Induk } \\
\text { Siswa) }\end{array}$ & CT ID & Permission \\
\hline $\mathbf{1 7 0 2 1 8 1 6}$ & 111 & \\
\hline $\mathbf{1 7 0 2 1 8 1 8}$ & 112 & \\
\hline $\mathbf{1 7 0 2 1 8 1 9}$ & 113 & $\begin{array}{c}\text { PVEVM } \\
\text { Admin }\end{array}$ \\
\hline $\mathbf{1 7 0 2 1 8 2 0}$ & 114 & \\
\hline $\mathbf{n}$ & $\mathrm{n}$ & \\
\hline
\end{tabular}

Pembuatan $C T$, user dan pengaturan permission, monitoring dan penghapusan $C T$ pada server PVE sebelum diterapkannya otomasi memiliki tahapan-tahapan seperti pada gambar 7.

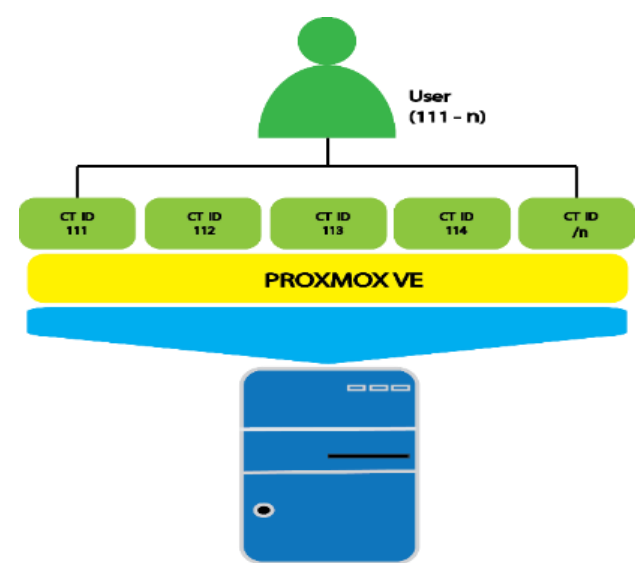

Gambar 3 Rancangan Sistem Manual PVE

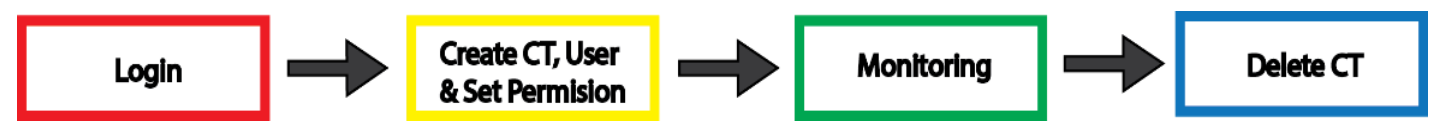

Gambar 4 Tahapan Pembuatan Sistem Manual Pada PVE 


\subsubsection{Rancangan Sistem Otomasi Proxmox Menggunakan Ansible}

Rancangan Rancangan sistem otomasi merupakan rancangan yang akan digunakan untuk melakukan otomasi untuk memanajemen $C T$, user dan pengaturan permission pada server $P V E$ berdasarkan data siswa. Dalam hal ini server PVE sudah terintegrasi dengan ansible, sehingga memanajemen $C T$, user dan pengaturan permission dapat dibuat secara otomasi. Seperti pada gambar 6.

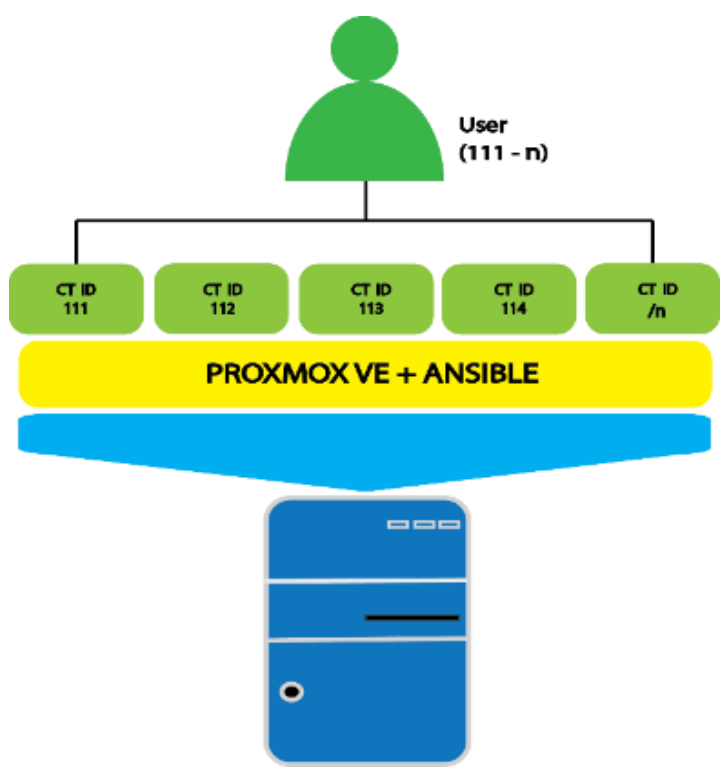

Gambar 5 Rancangan Sistem Otomasi PVE

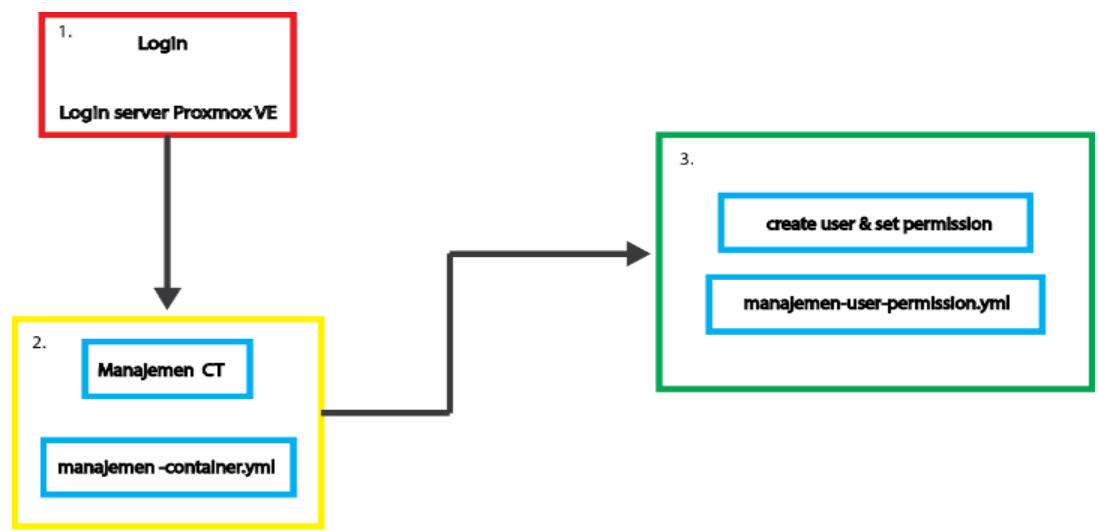

Gambar 6 Tahapan Manajemen CT, User dan Permission Secara Otomasi Pada PVE

Dalam memanajemen $C T$, User dan pengaturan permission secara otomasi, terdapat tahapan-tahapan yang dilakukan agar proses otomasi dapat berjalan. Tahapan tersebut dapat dilihat pada gambar 7 diatas.

Tahapan pertama yang dilakukan adalah dengan login ke server Ansible, kemudian untuk melakukan proses memanajemen $C T$ dengan mengakses file YAML dengan nama manajemencontainer.yml. Setelah itu mengisikan script untuk memanajemen $C T$ pada $P V E$ untuk mengeksekusi file YAML dengan mengetikan perintah ansible-playbook manajemencontainer.yml --skip-tags "start, stop, delete" karna ada beberapa tags yang kita jalankan saat memanajemen container. Selanjutnya memanajemen user dan permission dengan mengakses file YAML dengan nama manajemen-user-permission.yml. Setelah itu mengisikan script untuk memanajemen user dan permission pada PVE untuk mengeksekusi file YAML dengan 
mengetikan perintah ansible-playbook manajemen-user-permission.yml --skip-tags "remove, reset"

\subsubsection{Kebutuhan Perangkat Keras Dan Lunak}

Adapun kebutuhan perangkat keras dan perangkat lunak dalam penulisan skripsi ini adalah sebagai berikut:

\section{A. Kebutuhan Perangkat Keras (Hardware)}

1. Dengan menggunkan 1 (satu) unit computer yang didalamnya diinstalkan VMware workstation dan dibuatkan 2 (dua) virtual machin sebagai server PVE dan server ansible. Dan juga 1 (satu) unit computer itu juga akan difungsikan sebagai PC Client.

a. 1 server $P V E$ dengan spesifikasi sebagai berikut:

$\begin{array}{ll}\text { - Procesor } & : 1 \text { Core } \\ \text { - Hardisk } & : 40 \mathrm{~GB} \\ \text { - Memory } & : 4 \mathrm{~GB}\end{array}$

b. 1 server asnible dengan spesifikasi sebagai berikut:

-Procesor : 1 Core

-Hardisk $\quad: 15 \mathrm{~GB}$

-Memory $\quad: 2 \mathrm{~GB}$

-Sistem Operasi : CentOS 7

c. Komputer Client dengan spesifikasi sebagai berikut:

-Procesor

: Intel Core i5

-Hardisk $\quad: 1 \mathrm{~TB}$

-Memory $\quad: 8 \mathrm{~GB}$

-Sistem Operasi : Windows 10

B. Kebutuhan Perangkat Lunak (Software)

1. Ansible merupakan mesin otomasisasi Teknologi Informasi (TI) sederhana yang dapat mengotomasisasi cloud provisioning, manajemen konfigurasi, penerapan aplikasi, intraservice orchestration dan kebutuhan TI lainnya. Ansible diinstall pada PC Guru yang digunakan sebagai server ansible untuk melakukan otomasi.

2. Pip adalah singkatan dari Pip Installs Python atau PIP Installs Packages. pip adalah sebuah app store (atau biasa disebut sebagai package manager), kita bisa mencari, menginstall, memanage modules atau package pada installasi python. Pip terinstal pada server PVE.

3. Template CentOS 7 sebagai $O S$ pada computer server dan digunakan untuk instalasi sistem operasi pada $C T$.

4. Web browser adalah suatu program atau software yang digunakan untuk menjelajahi internet atau untuk mencari informasi dari suatu web yang tersimpan didalam komputer. Web browser digunakan untuk mengakses halaman dashboard web PVE melalui client.

\section{Evaluasi Prototype}

Pada tahap evalusasi, berisikan pernyataan penerimaan dan persetujuan sistem otomasi yang telah di ajukan kepada SMKN 6 Mataram.

\section{Pengkodean Sistem}

1. Installasi Dan Konfigurasi

Installasi dan konfigurasi

Pada tahap ini memuat tentang instalasi dan konfigurasi yang dilakukan pada masingmasing perangkat yang terlibat berdasarkan rancangan uji coba.

a. Instalasi dan konfigurasi server $P V E$

- Konfigurasi pengalamatan IP pada server 
- Install python-pip

- Install proxmoxer

b. Instalasi dan konfigurasi server Ansible

- Install epel-release

- Install ansible

c. Konfigurasi pada client

Konfigurasi pada client meliputi konfigurasi pengalamatan TCP/IP agar client dapat mengakses dashboard web PVE.

2. Pembuatan Kode Program

Pada tahap ini dilakukan pembuatan kode-kode program yang terkait dengan sistem otomasi yaitu:

a. pembuatan file manajemen CT dengan nama "manajemen-container.yml"

b. pembuatan file manajemen User dan Permission "manajemen-user-permission.yml"

E. Menguji Sistem

Pada tahap ini memuat tentang langkah-langkah untuk uji coba hasil konfigurasi menggunakan beberapa skenario uji coba. Dalam melakukan skenario uji coba memanajemen $C T$ seperti pembuatan, menjalankan, menghentikan dan menghapus $C T$ dan memanajemen user dan permission seperti pembuatan, mereset dan menghapus user dan permission. baik secara manual maupun otomasi, digunakan pembuatan menggunakan 1 data siswa sebanyak 5 kali dan menggunakan 24 data siswa sebanyak 5 kali, serta melakukan perhitungan waktu yang dibutuhkan untuk memanajemen $C T$ dan memanajemen user dan permission.

Tabel 3 Skenario Ujicoba

\begin{tabular}{|c|c|c|}
\hline Jumlah Ujicoba & Jenis pembuatan & Deskripsi \\
\hline $\begin{array}{l}5 \text { kali, dengan } \\
\text { menggunakan } 1 \\
\text { data siswa. }\end{array}$ & $\begin{array}{l}\text { Manual (melalui } \\
\text { dashboard web PVE) }\end{array}$ & $\begin{array}{l}\text { Menghitumg waktu minimum, maksimum, } \\
\text { dan rata-rata pembuatan, menjalankan, } \\
\text { menghentikan, menghapus } C T \text { dan } \\
\text { pembuatan, menghapus dan mereset semua } \\
\text { password user dan permission. }\end{array}$ \\
\hline $\begin{array}{l}5 \text { kali, dengan } \\
\text { menggunakan } 24 \\
\text { data siswa }\end{array}$ & $\begin{array}{l}\text { Otomasi (pembuatan } \\
\text { menggunakan ansible) }\end{array}$ & $\begin{array}{l}\text { Menghitumg waktu minimum, maksimum, } \\
\text { dan rata-rata pembuatan, menjalankan, } \\
\text { menghentikan, menghapus } C T \text { dan } \\
\text { pembuatan, menghapus dan mereset semua } \\
\text { password user dan permission. }\end{array}$ \\
\hline $\begin{array}{l}5 \text { kali, } \\
\text { menggunakan } 1 \\
\text { data siswa. }\end{array}$ & $\begin{array}{l}\text { Manual (melalui } \\
\text { dashboard web PVE) }\end{array}$ & $\begin{array}{l}\text { Menghitumg waktu minimum, maksimum, } \\
\text { dan rata-rata pembuatan, menjalankan, } \\
\text { menghentikan, menghapus } C T \text { dan } \\
\text { pembuatan, menghapus dan mereset semua } \\
\text { password user dan permission. }\end{array}$ \\
\hline $\begin{array}{l}5 \text { kali, } \\
\text { menggunakan } 24 \\
\text { data siswa. }\end{array}$ & $\begin{array}{l}\text { Otomasi (pembuatan } \\
\text { menggunakan ansible) }\end{array}$ & $\begin{array}{l}\text { Menghitumg waktu minimum, maksimum, } \\
\text { dan rata-rata pembuatan, menjalankan, } \\
\text { menghentikan, menghapus } C T \text { dan } \\
\text { pembuatan, menghapus dan mereset semua }\end{array}$ \\
\hline
\end{tabular}


password user dan permission.

\section{Hasil dan Pembahasan}

\subsection{Hasil Instalasi dan Konfigurasi}

Pada server dilakukan instalasi sistem operasi Proxmox Virtual Environment (PVE) dengan hasil instalasi seperti terlihat pada gambar 10.

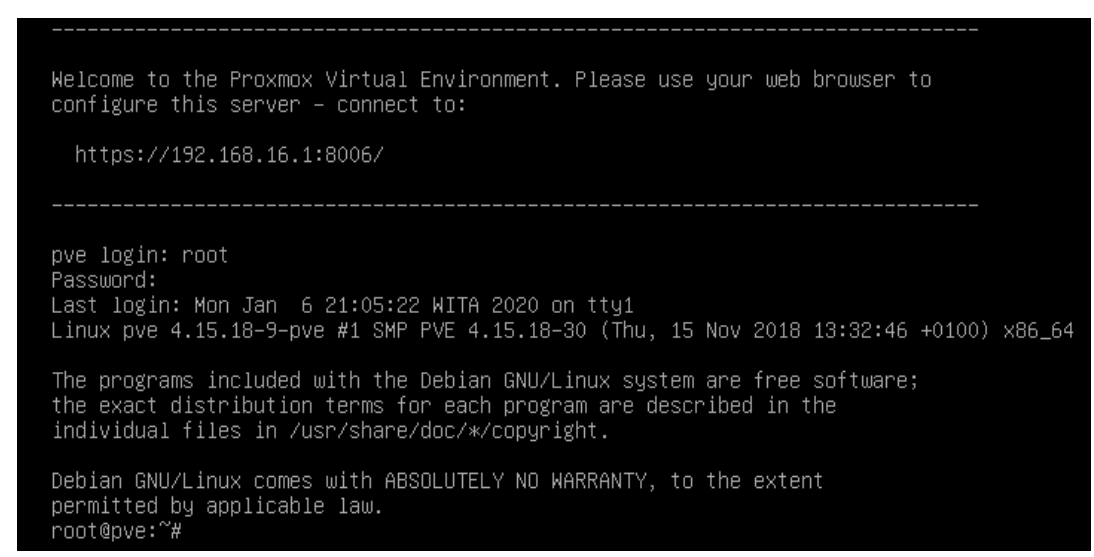

Gambar 10 Hasil Instalasi Proxmox VE

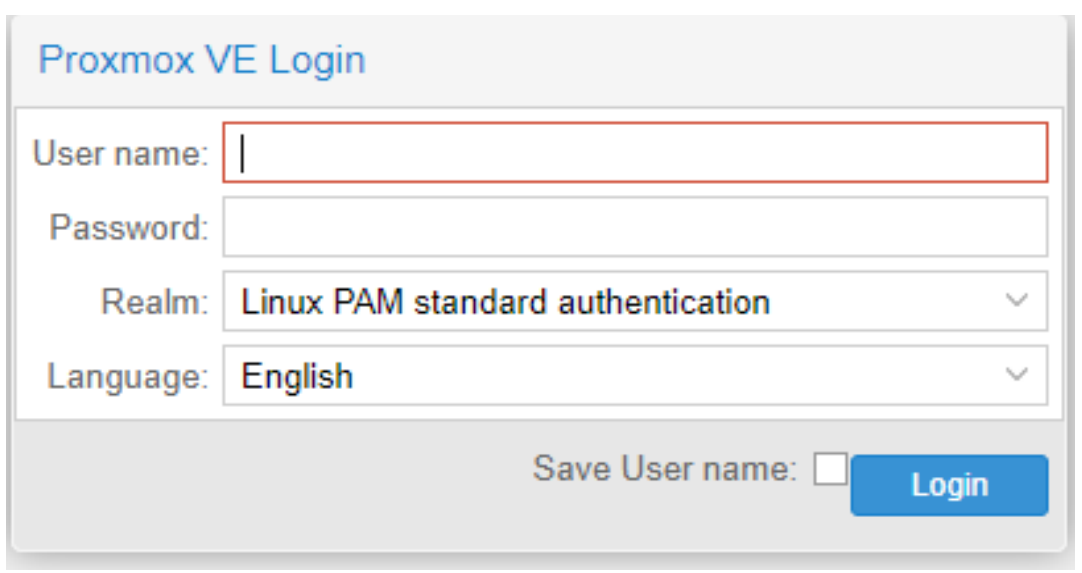

Gambar 11 Tampilan Login PVE Web

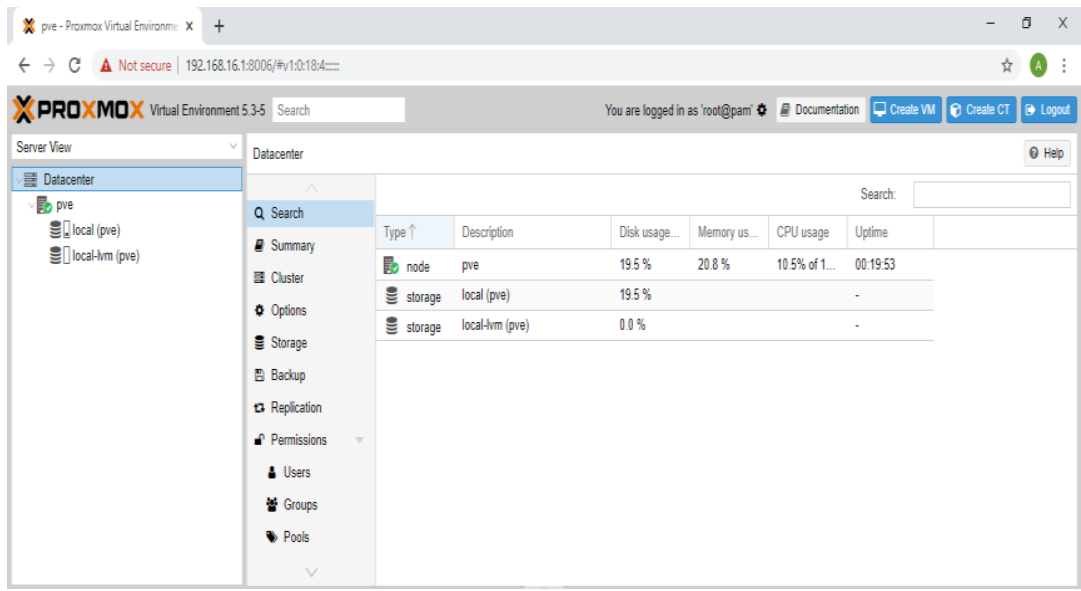

Gambar 12 Tampilan Dashboard Web Server Proxmox VE 
Terlihat kotak dialog otentikasi Proxmox VE Login. Login menggunakan browser ke server Proxmox VE dengan alamat IP https://192.168.16.1:8006 dan lengkapi isian dari "User name" dan "Password". Pada isisan "User name" masukan "root". Sedangkan pada isian "Password" masukan sandi login dari user "root" yaitu "12345678". Selain itu pastikan pilihan "Realm" adalah Linux PAM standard authentication serta untuk "Language" adalah "English", seperti gambar 11.

Terlihat pada PVE yang telah di install dan terdapat menu-menu lainnya yang membantu dalam memanagement ketika menggunakan server PVE sebagai management virtualization, seperti terlihat pada gambar 12 .

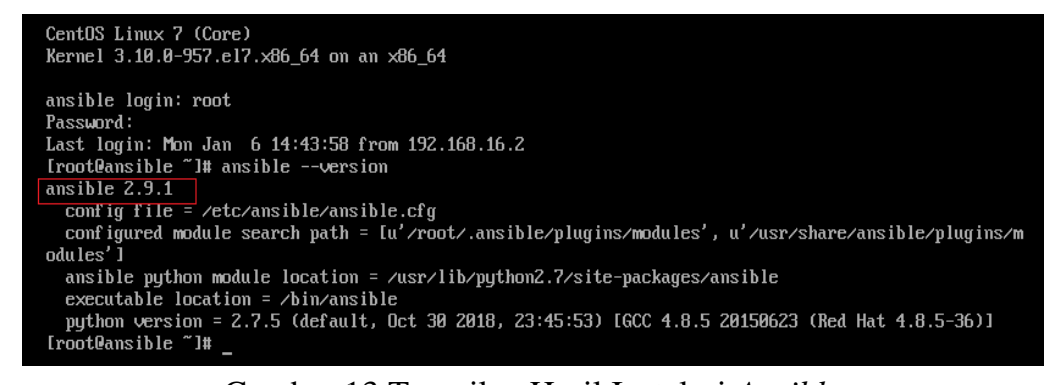

Gambar 13 Tampilan Hasil Instalasi Ansible

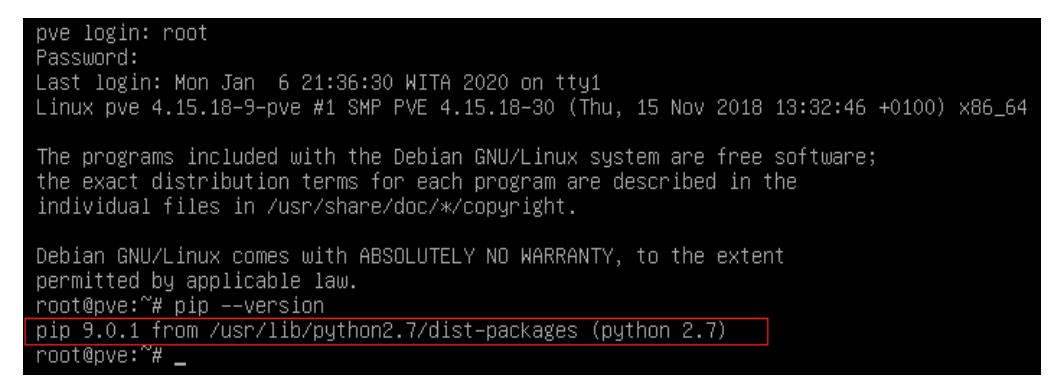

Gambar 14 Tampilan Hasil Instalasi Package PIP

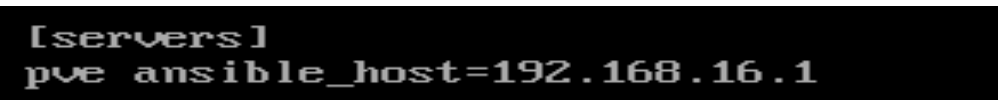

Gambar 15 Tampilan Hasil Konfigurasi File Hosts

Selanjutanya Pada Server Linux CentOs 7 dilakukan instalasi tools ansible yang digunakan untuk melakukan otomasi pada proxmox dan juga melakukan konfigurasi file host. Hasil instalasi dan konfigurasi ansible terdiri dari instalasi epel-release dan instalasi package ansible. Hasil akhir dari instalasi tools ansible pada server PVE, terlihat seperti pada gambar 13.

Terdapat package pip yang dibutuhkan ansible agar sistem otomasi pada server proxmox dapat berjalan, hasil dari instalasi package seperti terlihat pada gambar 14

Setelah instalasi package pada server proxmox dan ansible selesai, selanjutnya melakukan konfigurasi file hosts yang terdapat pada /etc/ansible/hosts dengan menambahkan ip dari server proxmox dengan alamat IP 192.168.16.1 agar ansible dapat berkomunikasi dengan proxmox, hasil dari konfigurasi file hosts, seperti terlihat pada gambar 15 berikut:

\subsection{Hasil Konfigurasi Client Windows 10}

Konfigurasi yang dilakukan pada client windows 10 adalah pengaturan alamat IP agar dapat terhubung dengan server proxmox Terlihat alamat IP yang digunakan adalah 192.168.16.2 dengan subnetmask 255.255.255.0. Hasil konfigurasi IP seperti terlihat pada gambar 16. 


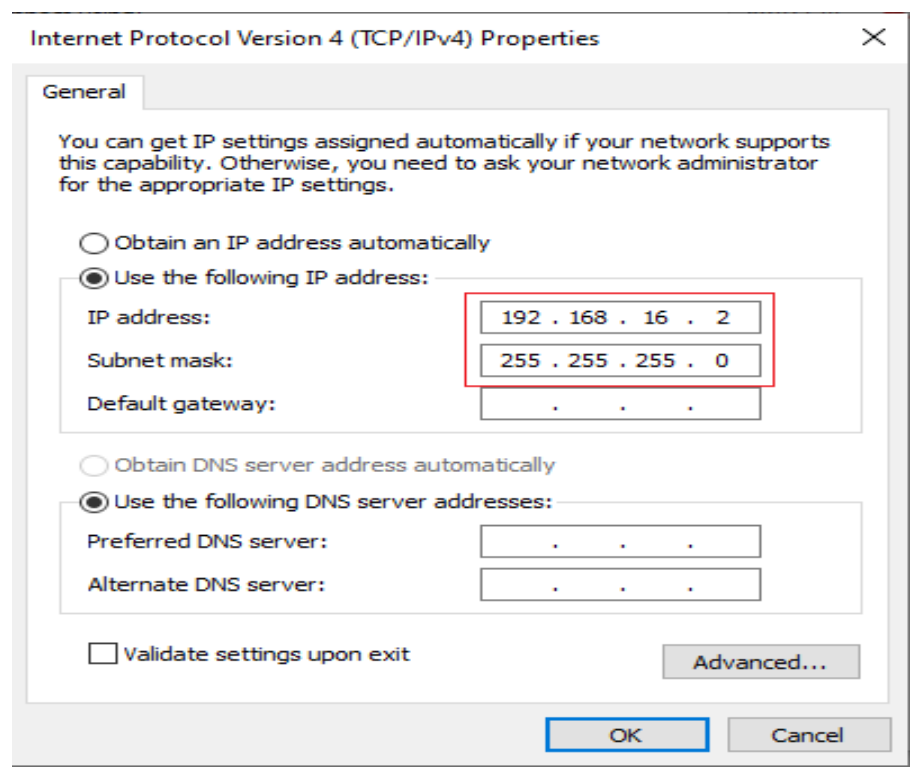

Gambar 16 Tampilan Hasil Konfigurasi Client

\subsection{Analisa Hasil Ujicoba}

Berdasarkan analisa hasil ujicoba yang telah dilakukan maka diperoleh analisa hasil ujicoba sebagai berikut:

1. Pembuatan, menjalankan, menghentikan dan menghapus $C T$. secara umum antara manual dengan otomasi berbeda. Pembuatan, menjalankan, menghentikan dan menghapus $C T$ secara manual hanya bisa dilakukan 1 (satu) kali dalam satu waktu. Sedangkan pembuatan, menjalankan, menghentikan dan menghapus $C T$ secara otomasi bisa membuat lebih dari 1 (satu) $C T$ dalam satu waktu secara bersamaan atau dalam satu kali eksekusi perintah menggunakan ansible.

2. Pembuatan, mereset, dan menghapus user \& Permission. secara umum antara manual dengan otomasi berbeda. Pembuatan, mereset, dan menghapus user \& Permission secara manual hanya bisa dilakukan 1 (satu) kali dalam satu waktu. Sedangkan pembuatan, mereset, dan menghapus User \& Permission secara otomasi bisa membuat lebih dari 1 (satu) user \& Permission dalam satu waktu secara bersamaan atau dalam satu kali eksekusi perintah menggunakan ansible.

3. Analisa waktu yang dibutuhkan untuk Pembuatan, menjalankan, menghentikan dan menghapus $C T$. Terdapat dua analisa perbandingan hasil ujicoba waktu Pembuatan, menjalankan, menghentikan dan menghapus $C T$. Pertama yaitu analisa hasil ujicoba antara waktu Pembuatan, menjalankan, menghentikan dan menghapus 1 (satu) $C T$ manual dan otomasi. Kedua yaitu analisa hasil Pembuatan, menjalankan, menghentikan dan menghapus 24 (dua puluh empat) CT sekaligus baik secara manual maupun secara otomasi menggunakan ansible. Hasil analisa yaitu perhitungan waktu sebanyak 5 (lima) kali percobaan secara manual dan otomasi, dapat terlihat rata-rata waktu pembuatan, menjalankan, menghentikan dan menghapus 1 (satu) CT. Selisih dari waktu pembuatan adalah 21 detik, selisih dari waktu menjalankan adalah 2 detik, Selisih dari waktu menghentikan adalah 3 detik dan selisih dari waktu penghapusan adalah 1 detik lebih cepat dilakuakan secara otomasi. Perbedaan waktu juga dipengaruhi oleh administrator ketika memasukan data yang akan diotomasi (human error). Dari hasil analisa perhitungan waktu sebanyak 5 (lima) kali percobaan secara manual dan otomasi, dapat terlihat rata-rata pembuatan, menjalankan, menghentikan dan menghapus 24 (dua puluh empat) $C T$. Selisih dari waktu pembuatan adalah 15 menit 14 detik, selisih dari waktu menjalankan adalah 02 menit 06 detik, Selisih dari waktu menghentikan adalah 03 menit 18 detik dan selisih dari 
waktu penghapusan adalah 02 menit 39 detik lebih cepat dilakuakan secara otomasi. Perbedaan waktu juga dipengaruhi oleh administrator ketika memasukan data yang akan diotomasi (human error).

4. Analisa waktu yang dibutuhkan untuk Pembuatan, mereset dan menghapus user \& permission. Terdapat dua analisa perbandingan hasil ujicoba waktu Pembuatan, mereset dan menghapus user \& permission. Pertama yaitu analisa hasil ujicoba antara waktu Pembuatan, mereset dan menghapus 1 (satu) user \& permission manual dan otomasi. Kedua yaitu analisa hasil Pembuatan, mereset dan menghapus 24 (dua puluh empat) user \& permission sekaligus baik secara manual maupun secara otomasi menggunakan ansible. Hasil analisa seperti berikut ini:

a. Dari hasil analisa perhitungan waktu sebanyak 5 (lima) kali percobaan secara manual dan otomasi, dapat terlihat rata-rata pembuatan, mereset, dan menghapus 1 (satu) user \& permission. lebih cepat dilakukan secara otomasi. Perbedaan waktu juga dipengaruhi oleh administrator ketika memasukan data yang akan diotomasi (human error).

b. Dari hasil analisa perhitungan waktu sebanyak 5 (lima) kali percobaan secara manual dan otomasi, dapat terlihat rata-rata pembuatan, mereset, dan menghapus 24 (dua puluh empat) user \& permission. Selisih dari waktu pembuatan adalah 5 menit 19 detik, selisih dari waktu mereset adalah 03 menit 18 detik dan selisih dari waktu penghapusan adalah 2 menit lebih cepat dilakuakan secara otomasi. Perbedaan waktu juga dipengaruhi oleh administrator ketika memasukan data yang akan diotomasi (human error).

\section{Kesimpulan}

Adapun kesimpulan yang dapat diambil berdasarkan hasil uji coba yang telah dilakukan adalah sebagai berikut:

1. Ansible dapat digunakan mengotomasi manajemen $C T$ baik dalam pembuatan, menjalankan, menghentikan dan menghapus $C T$ pada $P V E$ dalam mata pelajaran administrasi system jaringan di SMKN 6 Mataram.

2. Sistem Ansible dapat digunakan untuk mengotomasi manajemen user \& permission baik dalam pembuatan, mereset dan menghapus user \& permission pada $P V E$.

3. Sistem otomasi yang dibuat dapat mempercepat proses pembuatan, menjalankan, menghentikan dan menghapus 1 (satu) CT. Dilakukan sebanyak 5 (lima) kali percobaan dengan rata-rata Selisih waktu pembuatan adalah 21 detik, selisih dari waktu menjalankan adalah 2 detik, selisih dari waktu menghentikan adalah 3 detik dan selisih dari waktu penghapusan adalah 1 detik lebih cepat dilakukan secara otomasi dari pada dilakukan secara manual.

4. Sistem otomasi yang dibuat dapat mempercepat proses pembuatan, menjalankan, menghentikan dan menghapus 24 (dua puluh empat) $C T$. Dilakukan sebanyak 5 (lima) kali percobaan dengan rata-rata Selisih waktu pembuatan adalah 15 menit 14 detik, selisih dari waktu menjalankan adalah 2 menit 6 detik, Selisih dari waktu menghentikan adalah 3 menit 18 detik dan selisih dari waktu penghapusan adalah 2 menit 39 detik lebih cepat dilakukan secara otomasi dari pada dilakukan secara manual.

5. Sistem otomasi yang dibuat dapat mempercepat proses pembuatan, mereset, dan menghapus 1 (satu) user dan permission. Dilakukan sebanyak 5 (lima) kali percobaan dengan rata-rata Selisih waktu pembuatan adalah 5 detik, selisih dari waktu mereset adalah 9 detik, dan selisih dari waktu penghapusan adalah 6 detik lebih cepat dilakukan secara otomasi dari pada dilakukan secara manual.

6. Sistem otomasi yang dibuat dapat mempercepat proses pembuatan, mereset, dan menghapus 24 (dua puluh empat) user dan permission. Dilakukan sebanyak 5 (lima) kali percobaan 
dengan rata-rata Selisih waktu pembuatan adalah 5 menit 19 detik, selisih dari waktu mereset adalah 3 menit 18 detik, dan selisih dari waktu penghapusan adalah 2 menit lebih cepat dilakuakan secara otomasi dari pada dilakukan secara manual.

\section{Ucapan Terima Kasih}

Terimakasih kepada tim jurnal BITe yang telah memberikan kesempatan pada kami untuk mempublikasikan penelitian yang kami lakukan.

\section{Referensi}

[1] Arief Arfriandi, "Perancangan, implementasi, dan Analisis Kinerja Virtualisasi Menggunakan Proxmox Esx, Vmware dan Openstack," Jurnal Teknologi, vol. 5, no. 2, pp. 182-191, 2012.

[2] Y. Ariyanto, B. Harijanto, V. A. H. Firdaus, and S. N. Arief, "Performance analysis of Proxmox VE firewall for network security in cloud computing server implementation," IOP Conference Series: Materials Science and Engineering, vol. 732, no. 1, pp. 1-6, 2020, doi: 10.1088/1757-899X/732/1/012081.

[3] I. P. Hariyadi and A. Juliansyah, "Analisa Penerapan Private Cloud Computing Berbasis Proxmox Virtual Environment Sebagai Media Pembelajaran Praktikum Manajemen Jaringan," MATRIK : Jurnal Manajemen, Teknik Informatika dan Rekayasa Komputer, vol. 18, no. 1, pp. 1-12, 2018, doi: 10.30812/matrik.v18i1.329.

[4] S. R. Siregar, P. Studi, and T. Informatika, "Efesiensi Fisik Komputer Server dengan Menerapkan Proxmox Virtual Environment," Journal of Computer System and Informatics (JoSYC), vol. 1, no. 2, pp. 83-87, 2020.

[5] E. A. Didik Sudayana, "Virtualisasi Server Dengan Proxmox Untuk Pengoptimalisasian Penggunaan Resource Server Pada UPT Teknologi dan Komunikasi Pendidikan," SATIN - Sains dan Teknologi Informasi, vol. 3, no. 2, p. 8, 2014.

[6] W. Felter, A. Ferreira, R. Rajamony, and J. Rubio, "IBM Research Report An Updated Performance Comparison of VirtualMachines and Linux Containers," Computer Science, vol. 25297, pp. 25482-1407, 2012, [Online]. Available: http://domino.watson.ibm.com/library/CyberDig.nsf/home.

[7] Z. Wan, D. Lo, X. Xia, L. Cai, and S. Li, "Mining Sandboxes for Linux Containers," Proceedings - 10th IEEE International Conference on Software Testing, Verification and Validation, ICST 2017, pp. 92-102, 2017, doi: 10.1109/ICST.2017.16. 